\title{
Growth Analysis of a Sorghum Hybrid and its Parents ${ }^{1}$
}

\author{
P. T. Gibson and K. F. Schertz ${ }^{2}$
}

\section{ABSTRACT}

Growth rate, leaf area index, net assimilation rate, and distribution of dry matter among aboveground plant parts were determined for sorghum [Sorghum bicolor (L.) Moench] hybrid 'RS 610' and its parents throughout the growing season in a replicated field experiment. Dry weight and leaf area were measured twice weekly before flowering and weekly thereafter. The hybrid developed faster than its parents. It had greater leaf area than its parents until 1 week prior to flowering, and less leaf area than its parents thereafter. The hybrid had greater total dry weight than its parents throughout the growing season. The crop growth rate (CGR) of the hybrid was greater than that of either parent from emergence to panicle initiation, while net assimilation rate and relative growth rate did not differ among genotypes at this period. RS 10 outyielded its parents in grain, and had more kernels per panicle than the female parent, but did not differ from the male parent in this characteristic. The yield superiority of $R S 610$ was attributed mainly to the combination of the high CGR of the female parent during grain filling with the effective conversion of dry matter to grain of the male parent. More rapid seedling growth and a longer grain filling period were also advantages of the hybrid over its parents.

Additional index words: Crop growth rate, Net assimilation rate, Heterosis, Harvest index, Grain sorghum, Sorghum bicolor (L.) Moench, Hybrid vigor.

$\mathbf{H}$ YBRIDS are used for nearly all grain sorghum (Sorghum bicolor (L.) Moench) production in the USA and in an increasing percentage of world production as well. Identification of physiological traits associated with hybrid vigor could be usefill in choosing parents that are likely to produce a superior hybrid. Most studies of heterosis in sorghum have concentrated on grain yield components. These studies have shown that higher yields of the hybrid are generally due to more kernels per plant, sometimes to heavier kernels, or to both.

The few studies which have considered the effects of heterosis prior to maturity have all reported that sorglıum hybrids that show heterosis for grain yield also show heterosis for early growth $(1,8,10,12,14)$. Quinby (12) reported wider embryonic leaf blades, wider subsequent leaves, and larger panicles in 'CK60' $\times$ 'Tx7078' (RS610) and in 'A Redlan' $X$ Tx7078 than in their parents. Patanothai and Atkins (10) reported that hybrids designated as high heterosis ('Reliance' $\times$ Tx7078), medium heterosis (CK60 $\times$ 'Caprock') and low heterosis ('Martin' $X$ 'Texas 04') for grain yield showed corresponding levels of heterosis for dry matter accumulation prior to heading. Arnon and Blum (1) found that RS 610 accumulated

\footnotetext{
${ }^{1}$ Contribution of the Texas Agric. Exp. Stn. and USDA-ARS, College Station, TX 77843. Received 13 Sept. 1976.

" Former NSF graduate fellow, Texas A\&M Univ. (present address, ICRISAT, 1-11-256 Begumpet, Hyderabad 500016, A.P. India), and rescarch geneticist, USDA-ARS, College Station, TX 77843 .
}

dry matter faster than its parents during the first weeks after planting. They also found that at maturity RS 610 had less leaf dry weight than either of its parents, but still yielded more grain. They suggested that RS 610 had a greater net assimilation rate (NAR, rate of production of dry matter per unit of leaf area) than its parents. Krishnamurtliy et al. (8) compared the average NAR after head emergence of a widely grown Indian hybrid, 'CSH-1', with its parents, CK60 and 'IS 84', and found that the hybrid had a greater NAR than its parents when grown during the monsoon, but not when grown during the summer.

Rao and Venkateswarlu (14) studied heterosis in relation to dry matter production in four sorghum hybrids that had CK60 as the female parent. Two of the pollinator parents were improved Indian varieties, and two were lines from outside India (IS84 and 'IS 3691'). The latter were the male parents of $\mathrm{CSH}-1$ (CK60 $\times$ IS 84) and 'CSH-2' (CK60 $\times$ IS 3691). CSH-1 and CSH-2 showed heterosis for grain yield, while the other two hybrids did not. All four hybrids showed heterosis for dry matter production. The dry matter and leaf area data reported by Rao and Venkateswarlu were used to calculate NARs for each genotype for three periods: 35 days after planting to heading, heading to $50 \%$ anthesis, and anthesis to harvest. The hybrids generally had NARs approximately equal to or slightly greater than that of the parent with the higher NAR during each of the three periods. The lack of heterosis for grain yield in the two crosses involving improved Indian varieties was caused by a low harvest index (HI).

Studies in maize (Zea mays L.) indicate that there is heterosis for NAR during the first few weeks after planting. Voldeng and Blackman (16) compared the NARs of two maize hybrids with their parents. They concluded that the more rapid early growth of hybrids was due to higher NARs. In a later study, Donaldson and Blackman (2) reported that four of six hybrids exceeded both parents in NAR during the period of 2 to 3 weeks after planting.

The results of these studies prompted us to consider the growth relationships that might be important in hybrid sorghum. The object of our study was to determine if there are differences between grain sorghum hybrid RS 610 and its parents in growth rate, leaf area index, net assimilation rate, and dry matter distribution over the whole cycle of crop growth from planting to maturity.

\section{MATERIALS AND METHODS}

The experiment was conducted in 1974 on Miller clay loam at the Texas A \& $M$ Brazos Valley Agronomy Farm at College Station, Tex. $\left(30^{\circ} 35^{\prime} \mathrm{N}, 96^{\circ} 21^{\prime} \mathrm{W}\right)$. The hybrid, RS 610, and its parents TxB3197 (sometimes referred to as CK60) and Tx7078, were planted in a randomized block design with 10 
Table 1. Number of days from planting to specific stages of development of sorghum hybrid RS 610 and its parents. The number of days elapsed from the previous stage is included in parentheses.

\begin{tabular}{lcccc}
\hline & \multicolumn{4}{c}{ Days after planting } \\
\cline { 2 - 5 } $\begin{array}{c}\text { Hybrid and } \\
\text { parents }\end{array}$ & Emergence & $\begin{array}{c}\text { Panicle } \\
\text { initiation }\end{array}$ & Anthesis & $\begin{array}{c}\text { Physiological } \\
\text { maturity }\end{array}$ \\
\hline RS 610 & 7 & $36(29)$ & $63(27)$ & $98(35)$ \\
TxB3197 & 7 & $37(30)$ & $67(30)$ & $100(33)$ \\
Tx7078 & 7 & $39(32)$ & $67(30)$ & $100(33)$ \\
SD & & & 0.3 & 0.4 \\
\hline
\end{tabular}

Table 2. Leaf area index (LAI) and total dry weight (DW) of sorghum hybrid RS 610 and its parents from 13 to 41 days after planting.

\begin{tabular}{clllllll}
\hline \multirow{2}{*}{$\begin{array}{c}\text { Days after } \\
\text { planting }\end{array}$} & \multicolumn{3}{c}{ LAI* } & & \multicolumn{3}{c}{ DW, kg/ha* } \\
\cline { 2 - 4 } \cline { 6 - 7 } & RS 610 & TxB3197 & Tx7078 & & RS 610 & TxB3197 & Tx7078 \\
\hline 13 & $0.0058 \mathrm{a}$ & $0.0045 \mathrm{~b}$ & $0.0055 \mathrm{a}$ & & $2.33 \mathrm{a}$ & $1.89 \mathrm{~b}$ & $1.88 \mathrm{~b}$ \\
20 & $0.0249 \mathrm{a}$ & $0.0181 \mathrm{~b}$ & $0.0193 \mathrm{~b}$ & & $9.95 \mathrm{a}$ & $7.84 \mathrm{~b}$ & $7.93 \mathrm{~b}$ \\
27 & $0.110 \mathrm{a}$ & $0.083 \mathrm{~b}$ & $0.086 \mathrm{~b}$ & & $44.0 \mathrm{a}$ & $33.9 \mathrm{~b}$ & $34.5 \mathrm{~b}$ \\
34 & $0.475 \mathrm{a}$ & $0.292 \mathrm{~b}$ & $0.336 \mathrm{~b}$ & & $239 \mathrm{a}$ & $144 \mathrm{~b}$ & $160 \mathrm{~b}$ \\
41 & $1.448 \mathrm{a}$ & $0.975 \mathrm{~b}$ & $1.036 \mathrm{~b}$ & $898 \mathrm{a}$ & $608 \mathrm{~b}$ & $591 \mathrm{~b}$ \\
\hline
\end{tabular}

* Means in horizontal rows pertaining to LAI or DW followed by the same letter are not significantly different at $\mathbf{P}=0.05$ by Duncan's Multiple Range Test.

replications. Plots were six rows wide and $6 \mathrm{~m}$ long, with the inside four rows used for sampling. Plots were overseeded and thinned to 7 to $10 \mathrm{~cm}$ between plants with $67 \mathrm{~cm}$ between rows $\left(165,000\right.$ plants $\left.\cdot \mathrm{ha}^{-1}\right)$. Tillers were removed while still small to reduce variability among main culms. The experimental area was fertilized with $620 \mathrm{~kg} \cdot \mathrm{ha}^{-1}$ of $12-12-12$ the December before planting. An additional $320 \mathrm{~kg} \cdot \mathrm{ha}^{-1}$ of $33-0-0$ was applied 39 days after planting. Rainfall was supplemented with irrigation five times during the season so that there was never a shortage of moisture in the soil. The total amount supplied $(52 \mathrm{~cm})$ exceeded the potential evapotranspiration $(50 \mathrm{~cm})$ as estimated by Penman's formula (11). Daily radiation and daily minimum and maximum air temperatures at $2 \mathrm{~m}$ above the ground (averaged over each harvest interval) had ranges of 17.7 to 28.2 $\mathrm{MJ} \cdot \mathrm{m}^{-2}$ day $^{-1}, 16.0$ to $23.7 \mathrm{C}$, and 29.6 to $34.5 \mathrm{C}$, respectively (5). No definite patterns were observed between growth rates and fluctuations of radiation or temperature.

Dates of $50 \%$ emergence, panicle initiation, anthesis, and physiological maturity were determined. The criterion for panicle initiation was the formation of raspberry-like bumps on the growing point $\langle 9)$; for anthesis it was the first protrusion of anthers; for physiological maturity it was the formation of a black layer in the hilar region of kernels four-fifths of the way down the panicle. Further detail is given elsewhere (5).

Forty plants of each genotype were harvested for leaf area and dry weight measurements twice a week from 13 days after planting until 76 days after planting, and once weekly thereafter until maturity at 100 days. One plant in each of four rows/plot was harvested each sampling date. Sampling began near one end of the row and progressed toward the other end. At least two plants were left between currently harvested plants and previ. ously harvested areas. Abnormally small plants were not sampled, so a slight upward bias was expected in dry matter and yield data. To estimate this bias, $2 \mathbf{m}^{2}$ of each plot was har. vested at maturity, and the dry weight compared with that of the usual sample of four plants.

Exposed green leaf-blade area per plant was measured and converted to leaf area index (LAI, leaf area per unit ground area). The average density of 165,000 plants $\cdot \mathrm{ha}^{-1}$ was used for all calculations. Leaves from harvested plants were measured using a photoelectric planimeter (Hayashi Denko Type AAM-5). ${ }^{3}$ Any brown portions of leaves were excluded from leaf area measurements.

${ }^{3}$ Mention of a trademark or proprietary product does not constitute a guarantee or warranty of the product by the USDA and does not imply its approval to the exclusion of other products that also may be suitable.

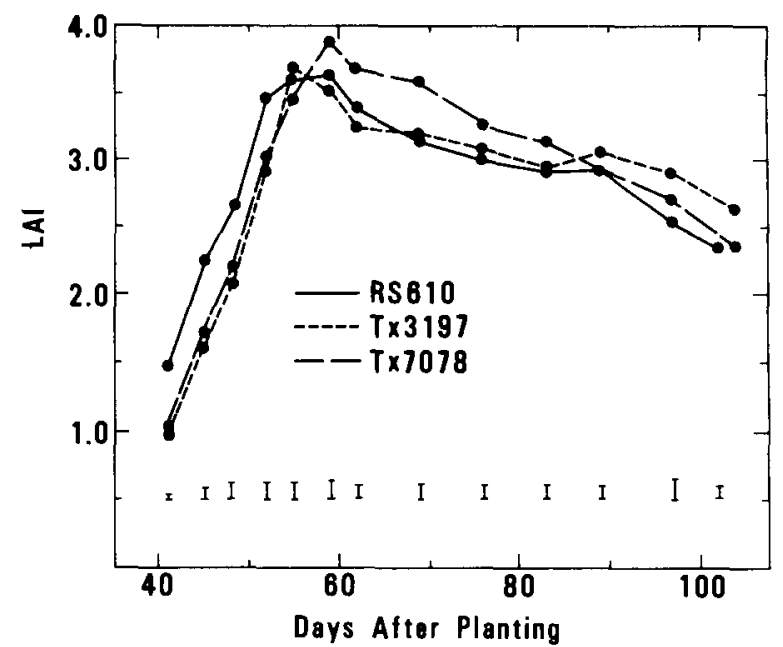

Fig. 1. Leaf area index (LAI) of sorghum hybrid RS 610 and its parents. Vertical bars are standard errors. (LAIs prior to 45 days after planting are shown in Table 2).

Plants were cut below the soil surface to recover the crown, and roots were discarded. They were divided into stems (including leaf sheaths), leaf blades, senescent parts, panicles, and grain, and were dried in a $70 \mathrm{C}$ forced air oven for 4 days.

Crop growth rate (CGR, rate of dry matter accumulation per unit land area), relative growth rate (RGR, rate of dry matter accumulation per unit dry matter already present), and net assimilation rate (NAR, rate of dry matter accumulation per unit leaf area) were calculated for each interval between harvests using standard formulas (13). Harvest index (HI, grain weight/total plant weight) was calculated for the final harvest.

\section{RESULTS AND DISCUSSION}

After emergence, the hybrid reached all stages of physiological development earlier than either parent (Table 1). Even as young seedlings the hybrid plants grew more vigorously than parental plants. The hybrid spent fewer days than its parents in the vegetative and panicle development periods, but spent two days more in the grain filling period.

\section{Leaf Area Index and Total Dry Weight}

The hybrid had a larger L.AI than either of its parents from the first harvest at 13 days after planting until 55 days after planting (Table 2 shows 13-41 days and Fig. 1 shows the remainder). From 55 days on, both parents either equalled or exceeded the hybrid in LAI. Total leaf numbers for RS 610, TxB3197, and $\mathrm{T} \times 7078$ were $15.8 \pm 0.1,16.5 \pm 0.2$, and $16.4 \pm$ 0.2 respectively. Each leaf appeared earlier on the hybrid than did the corresponding leaf on either parent. The hybrid exceeded each parent in the size of fully expanded individual leaves from leaf 1 to leaf 11, while each parent exceeded the hybrid in leaf size from leaf 13 to the flag leaf.

The hybrid exceeded each parent in total aboveground dry weight throughout the duration of growth (Table 2 shows 13 to 41 days and Fig. 2 shows the remainder). The greater total dry weight and leaf area of the hybrid on a given day in the early stages of growth reflected the faster morphological development (Table 1) of the hybrid relative to its parents. At anthesis, the dry weights of all three genotypes were 


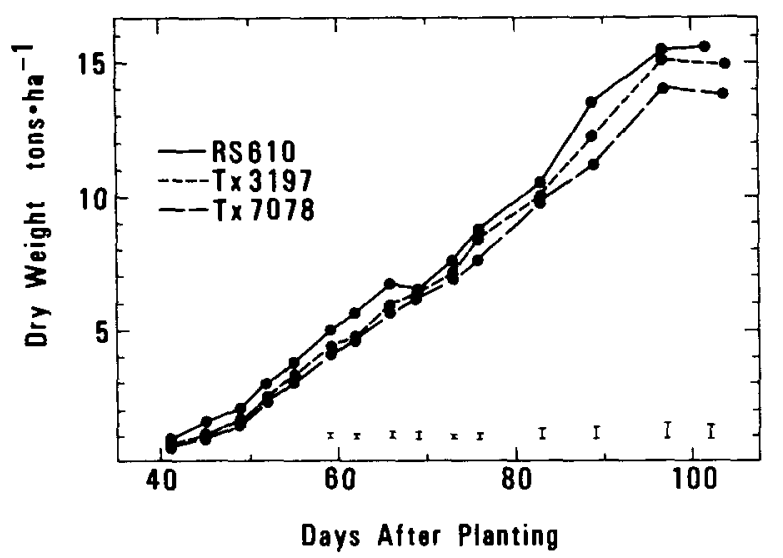

Fig. 2. Total aboveground dry weights of sorghum hybrid RS 610 and its parents. Vertical bars are standard errors. (Dry weights prior to 45 days after planting are shown in Table 2).

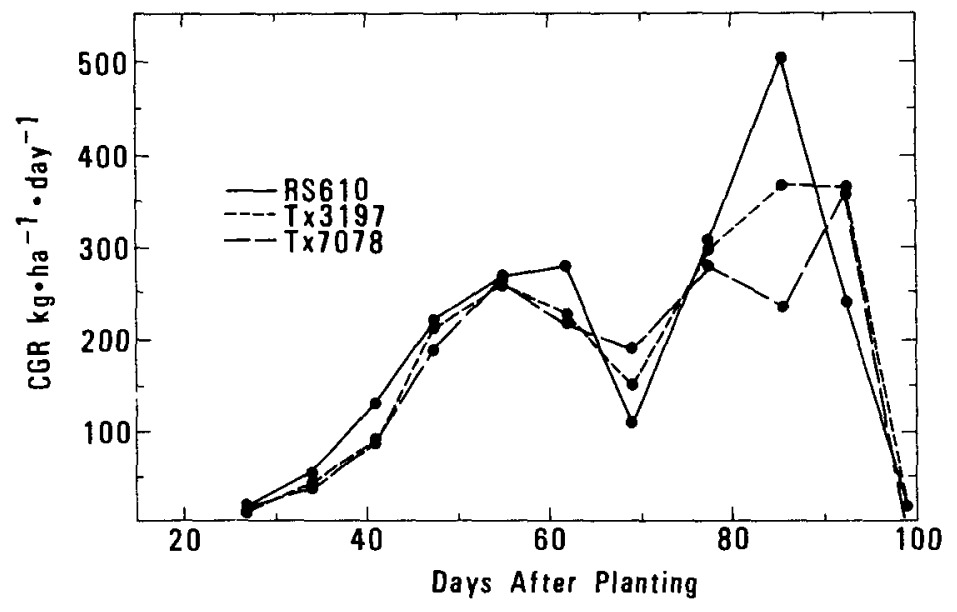

Fig. 3. Crop growth rate (CGR) of sorghum hybrid RS 610 and its parents. CGR for TXB3I97 and Tx7078 at I00 days after planting were -27 and $-60 \mathrm{~kg} \cdot \mathrm{ha}^{-1} \cdot \mathrm{day}^{-1}$, respectively.

nearly equal. During the grain filling period, the hybrid again exceeded its parents in total dry weight due to more grain production.

\section{Growth Rate and Net Assimilation Rate}

The hybrid exceeded each parent in crop growth rate (CGR) from emergence through 41 days after planting (Fig. 3) and it exceeded Tx7078 in the average CGR during grain filling. All genotypes had reduced CGRs during the time near flowering (Fig. 3). Low growth rates of sorghum at the time of flowering can be noted in the data of others; e.g., Knell (7) Fig. 15, and Reeves (15) Fig. 19. The low growth rates in our study during this period could have been due to weather effects or to the lack of an actively growing sink. Leaves, stem, and panicle were fully developed, and did not gain much dry weight after flowering. There are reports that the level of plotosynthetic activity in other species is influenced by sink size $(3,6)$. All three genotypes in our study had increased CGRs during grain filling, and reached their maximum CGRs during this period. No geno-

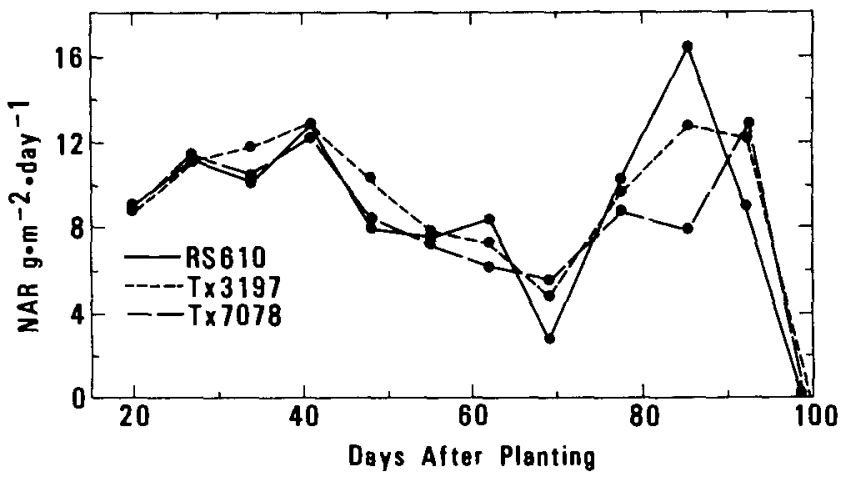

Fig. 4. Net assimilation rate (NAR) of sorghum hybrid RS 610 and its parents. NAR for TxB3197 and Tx7078 at 100 days after planting were -0.66 and $-2.24 \mathrm{~g} \cdot \mathrm{m}^{-2} \cdot$ day $^{-1}$, respectively.

typic differences were discernable in RGR at any period. Thus the CGR was always proportional to the dry weight present. Maximum RGR was $0.35 \mathrm{~g} \cdot \mathrm{g}^{-1}$ day $^{-1}$ occurring at 27 to 31 days after planting.

The hybrid did not exceed either parent in net assimilation rate before flowering (Fig. 4). Therefore, the greater CGR of the hybrid prior to 45 days after planting was due to the greater LAI of the hybrid $(\mathrm{CGR}=\mathrm{LAI} \times \mathrm{NAR})$. In contrast, during the grain filling period, the higher NAR of the hybrid was responsible for the difference in CGR between the hybrid and Tx7078 since the LAI of the hybrid was lower.

\section{Dry Matter Distribution and Grain Yield}

There were no differences among the three genotypes in partitioning of dry matter between leaves and stem until 24 days after planting. Beginning at 24 days and continuing to the final harvest, TxB3197 had a larger percentage of its dry weight in the stem than did RS 610, while Tx7078 had a larger percentage of dry matter in its leaves than did RS 610. From 55 days after planting to the final harvest, the hybrid had a smaller percentage of its dry weight in the leaves than either parent.

From 62 days after planting to the final harvest, both RS 610 and Tx7078 exceeded TxB3197 in the percentage of total dry weight in the panicle and grain. This was due in part to greater translocation of stored materials from the stem to the head in RS 610 and $T \times 7078$ than in TxB3197. In RS 610 and Tx7078, translocation of stored materials from the stem to the grain was estimated to contribute $10 \%$ of the grain weight, while in TxB3197 this was almost zero (Fig. 5). Fischer and Wilson (4) estimated from ${ }^{14} \mathrm{C}$ translocation studies of sorghum that materials stored beofre anthesis and later translocation to the grain accounted for $12 \%$ of the final grain weight.

Our data support the conclusion of Arnon and Blum (l) that RS 610 had an earlier and more complete transfer of assimilates from stover to head production. The growth rate of the leaves and stem of the hybrid started to decline several days earlier than it did in the parents (Fig. 5). The complete transfer of assimilates to grain production shortly after an- 




Fig. 5. Growth rate of plant parts of sorghum hybrid RS 610 and its parents.

Table 3. Yield and yield components of sorghum hybrid RS 610 and its parents.

\begin{tabular}{|c|c|c|c|c|c|c|}
\hline \multirow{2}{*}{$\begin{array}{l}\text { Hybrid and } \\
\text { parents }\end{array}$} & \multicolumn{3}{|c|}{ DW } & \multirow{2}{*}{$\begin{array}{c}\text { Harvest } \\
\text { index }\end{array}$} & \multirow{2}{*}{$\begin{array}{c}\text { Kernels/ } \\
\text { panicle }\end{array}$} & \multirow{2}{*}{$\begin{array}{c}\text { Wt. } / 1,000 \\
\text { kernels }\end{array}$} \\
\hline & Grain & Stover & Total & & & \\
\hline & \multicolumn{3}{|c|}{ metric tons/ha } & $\%$ & & $\mathrm{~g}$ \\
\hline $\begin{array}{l}\text { RS } 610 \\
\text { TxB3197 } \\
\text { Tx7078 }\end{array}$ & $\begin{array}{l}7.52 \mathrm{a} * \\
5.82 \mathrm{c} \\
6.37 \mathrm{~b}\end{array}$ & $\begin{array}{l}8.09 \mathrm{~b} \\
9.02 \mathrm{a} \\
7.23 \mathrm{c}\end{array}$ & $\begin{array}{l}15.6 \mathrm{a} \\
14.8 \mathrm{ab} \\
13.6 \mathrm{~b}\end{array}$ & $\begin{array}{l}48.0 \mathrm{a} \\
39.2 \mathrm{~b} \\
46.9 \mathrm{a}\end{array}$ & $\begin{array}{l}1,634 \mathrm{a} \\
1,401 \mathrm{a} \\
1,656 \mathrm{a}\end{array}$ & $\begin{array}{l}28.1 \mathrm{a} \\
25.2 \mathrm{~b} \\
23.5 \mathrm{c}\end{array}$ \\
\hline
\end{tabular}

* Means in vertical columns followed by the same letter are not significantly different at $\mathrm{P}=0.05$ by Duncan's Multiple Range Test. Grain moisture was $6 \%$.

Table 4. Grain yield of sorghum hybrid RS 610 and its parents expressed as a product of length of time in grain filling, CGR, and conversion percentage (grain weight as a percentage of dry matter increase after anthesis).

\begin{tabular}{lcccc}
\hline $\begin{array}{c}\text { Hybrid and } \\
\text { parents }\end{array}$ & $\begin{array}{c}\text { Days in } \\
\text { grain filling } \\
(1)\end{array}$ & $\begin{array}{c}\text { Avg. } \\
\text { CGR } \\
(2)\end{array}$ & $\begin{array}{c}\text { Conversion } \\
\text { percentage } \\
(3)\end{array}$ & $\begin{array}{c}\text { Grain yield } \\
\left(1 \times 2 \times 3 \times 10^{-5}\right)\end{array}$ \\
\hline & & $\mathrm{kg}^{*}$ ha $^{-1}$ :day $^{-1}$ & & metric tons/ha \\
RS 610 & 35 & 275 & 78.1 & 7.52 \\
TxB3197 & 33 & 267 & 66.1 & 5.82 \\
Tx7078 & 33 & 243 & 79.5 & 6.37 \\
\hline
\end{tabular}

thesis in the hybrid is evident in contrast to the continued vegetative growth of the parents.

RS 610 exceeded Tx7078 by $16 \%$ and TxB3197 by $28 \%$ in grain yield (Table 3 ). RS 610 exceeded both parents in kernel weight, whereas Tx7078 had as many kernels as RS 610. All yields reported are from the sample of four plants/plot in order to correspond to the growth data presented. The larger sample of $2 \mathrm{~m}^{2} /$ plot reflected the same trends between the hybrid and its parents in all characters measured. Differences between the parents and hybrid were somewhat greater in the larger sample since the hybrid was more uniformly vigorous than its parents. Thus, reporting data from the smaller sample (Table 3) underestimates differences.

Grain yield can be expressed as the product of number of days in the grain filling period, the average CGR during this period, and the percentage of the dry matter produced during this period which, was stored in the grain (conversion percentage) (Table 4). Grain production is a complex biological process, and although this partitioning is an obvious oversimplification, it does help identify factors which contribute to yield differences. The partitioning indicates that the hybrid derived its superior yield from a $6 \%$ longer grain filling period than either parent, an $11 \%$ greater CGR than Tx7078, and an $18 \%$ greater conversion of dry matter to grain than TxB3197. Since Tx7078 had as many kernels as RS 610 , and had roughly as much translocation from the stem to grain as RS 610, the primary yield limitation for Tx7078 appeared to be dry matter production. On the other hand, TxB3197 had sufficient dry matter production, but was limited in translocation to the grain. Thus RS 610 achieved the majority of its yield advantage by combining the high crop growth rate of TxB3197 with the effective conversion of dry matter to grain of $T \times 7078$. This agrees with the findings of Arnon and Blum (1) that these same characteristics contribute to the yield superiority of RS $610 \mathrm{com}$ pared to its parents in both dryland and irrigated conditions in Israel.

Further studies are needed to determine whether the factors responsible for RS 610's outyielding its parents are also responsible for other hybrids outyielding their parents. If some sorghum hybrids are superior to their parents because of complementary growth and yield characteristics, it might be possible to develop superior hybrids by selecting parents which complement each other. This could be a practical procedure if heritability is high and selection efficient for the desired characteristic. Selection of parents might be based on CGR and harvest index (HI) by measuring dry weight at anthesis and dry weight and HI at maturity. Some advantages of hybrids, such as more rapid early growth and a longer grain filling period, could not be identified in the parents, and these would have to be determined directly from hybrids.

It is not known if high yielding pure-line cultivars possess the same growth characteristics as superior hybrids. It is conceivable that if CGR and HI are primarily additively inherited, improved pure lines could be developed by combining these characteristics.

\section{REFERENCES}

1. Arnon, I., and A. Blum. 1964. Response of hybrid and selfpollinated sorghum varieties to moisture regime and intrarow competition. Israel J. Agric. Res. 14:45-53.

2. Donaldson, C., and G. E. Blackman. 1973. A further analysis of hybrid vigor in Zea mays during the vegetative phase. Ann. Bot. N. S. 37:905-917.

3. Eastin, J. A., and E. T. Gritton. 1969. Leaf area develop. ment, light interception, and growth of canning peas (Pisum sativum L.) in relation to plant population and spacing. Agron. J. 61:612-615. 
4. Fischer, K. S., and G. L. Wilson. 1971. Studies of grain production in Sorghum vulgare. I. The contribution of preflowering photosynthesis to grain yield. Aust. J. Agric. Res. 22:33-37.

5. Gibson, P. T. 1975. The effect of heterosis on growth rate and net assimilation rate in grain sorghum. M.S. thesis. Texas A\&M Univ., College Station.

6. Humphries, E. C., and G. N. Thorne. 1964. The effect of root formation on photosynthesis of detached leaves. Ann. Bot. N. S. 28:391-400.

7. Knell, F. A. 1972. Growth and dry matter accumulation in grain sorghum. M.S. thesis. Univ. Missouri, Columbia.

8. Krishnamurthy, K., B. G. Rajashekara, M K. Jagannath, A. Bomme Gowda, G. Raghunatha, and N. Venugopal. 1973. Photosynthetic efficiency of sorghum genotypes after head emergence. Agron. J. 65:858-860.

9. Lane, H. C. 1963. Effect of light quality on maturity in the milo group of sorghum. Crop Sci. 3:496-499.

10. Patanothai, Aran, and R. E. Atkins. 1971. Heterotic response for vegetative growth and fruiting development in grain sorghum, Sorghum bicolor (L.) Moench. Crop Sci. 11: 839-843.

11. Penman, H. L. 1948. Natural evaporation from open water, bare soil, and grass. Proc. R. Soc. (London) A193:120-145.

12. Quinby, J. R. 1970. Leaf and panicle size of parents and hybrids. Crop Sci. 12:690-691.

13. Radford, P. J. 1967. Growth analysis formulae-their use and abuse. Crop Sci. 7:171-175.

14. Rao, N. G. P., and J. Venkateswarlu. 1971. Genetic analysis of some exotic $\times$ Indian crosses in sorghum. III. Heterosis in relation to dry matter production and nutrient uptake. Indian J. Genet. Plant Breed. 31:156-176.

15. Reeves, H. E. 1971. Growth and dry matter accumulation in grain sorghum. Ph.D. thesis. Kansas St. Univ., Manhattan. (Libr. Cong. Card No. Mic. 72-31345). Univ. Microfilms. Ann Arbor, Mich. (Diss. Abstr. 32:1962B).

16. Voldeng, H. D., and G. E. Blackman. 1973. An analysis of the components of growth which determine the course of development under field conditions of selected inbreds and their hybrids of Zea mays. Ann. Bot. N. S. 37:539-552. 